\title{
Thermophilic biohydrogen production from palm oil mill effluent (POME) using suspended mixed culture
}

\begin{abstract}
A batch study was conducted to determine the fate of carbohydrate and oil that are present in palm oil mill effluent (POME) during the biohydrogen fermentation process. Sucrose and crude palm oil (CPO) were chosen as substrates and the kinetic profile indicated that mainly sucrose was metabolised by the mixed sludge. The hydrogen yield based on the COD of sucrose added was $146 \mathrm{~cm} 3 \mathrm{~g} 1$ which is equivalent to a hydrogen to hexose mole ratio of 2.5. The free fatty acids from hydrolysed CPO were not metabolised further which render insignificant generation of hydrogen and volatile fatty acids from oil-based substrate. The average continuous biohydrogen production rate (HPR) from a unit volume of POME under thermophilic condition at $55 \mathrm{C}$ was $2.64 \mathrm{~m} 3 \mathrm{~m} 3 \mathrm{~d} 1$ at a hydraulic retention time (HRT) of 4 days. Hydrogen constitutes up to 52\% of the total biogas and methane was not detected over the 60 day continuous operation. The hydrogen yield (i.e. based on mole ratio of hydrogen to hexose) was 1.72 with an average carbohydrate conversion efficiency of 58\%. These limit the potential of recovering more hydrogen energy from POME under current operating conditions.
\end{abstract}

Keyword: Biohydrogen; Anaerobic fermentation; Palm oil mill effluent; Thermophilic 